\title{
PERFIL SOCIODEMOGRÁFICO DOS PEDIATRAS DE FEIRA DE SANTANA
}

\author{
$\underline{\text { Jannine Rios Santos Serra }^{1} \text {; Tatiana de Oliveira Vieira }}{ }^{2}$; Graciete Oliveira Vieira ${ }^{3}$; \\ Letícia Silva Caires ${ }^{4}$ \\ 1. Bolsista PIBIC/CNPq, Graduando em Medicina da Universidade Estadual de Feira de Santana, e-mail: \\ janninerios@hotmail.com \\ 2. Orientadora. Professora Adjunta do Departamento de Saúde da Universidade Estadual de Feira de Santana, e-mail: \\ tatianaovieira@gmail.com \\ 3. Participante do projeto. Professora Titular do Departamento de Saúde da Universidade Estadual de Feira de \\ Santana, e-mail: gracieteovieira@gmail.com \\ 4. Participante do projeto ou núcleo tal, Departamento de Nome, Universidade Estadual de Feira de Santana, e-mail: \\ leticiacaires04@hotmail.com
}

\section{PALAVRAS-CHAVE: Pediatria, História, Hábitos Alimentares}

\section{INTRODUÇÃO}

A atuação do pediatra tem importante papel na sociedade, na qual interfere de maneira indiscutível na saúde infanto-juvenil, no que diz respeito ao acompanhamento do crescimento e do desenvolvimento, direcionamento dos hábitos alimentares e orientação vacinal, higiene e psicossocial (SANTIAGO, 2003). Nesse contexto, é importante saber o perfil sociodemográfico dos pediatras que acompanham e definem os cuidados de saúde de crianças e adolescentes do município e região, uma vez que o homem é fruto da interação com o ambiente, que pode condicionar o seu comportamento, modo de pensar, bem como interferir nas definições de ações na sua área de trabalho. $\mathrm{O}$ objetivo do atual estudo foi descrever o perfil dos pediatras de Feira de Santana.

\section{MATERIAIS E MÉTODOS}

Tipo de estudo - Foi realizado um estudo descritivo de corte transversal com o intuito de saber as características sociodemográficas dos médicos pediatras que atendem crianças e adolescentes na cidade de Feira de Santana e municípios vizinhos.

Instrumento de coleta de dados - Foi construído um questionário com informações sobre as características sociodemográficas que incluiu questões sobre: filiação, data de nascimento, naturalidade, número de filhos, local em que concluiu a graduação, ano de conclusão do Curso de Medicina, ano que começou a trabalhar em Feira de Santana, atuação em outro municípios, subespecialidade, especialização sob a forma de Residência Médica, título de especialista, registro da especialidade como pediatra, realização de pós-graduação, publicações científicas, dados relevantes de sua atuação profissional, contribuição em ações voluntárias e sócio da Sociedade Brasileira de Pediatria.

Coleta de dados - Foi realizada uma busca ativa dos pediatras, no ano de 2018, através do cadastro existente na Sociedade de Pediatria de Feira de Santana (SOPEFS) e do cadastro dos residentes de Pediatria do Hospital Estadual da Criança. A seguir, foram identificados os profissionais vivos (ativos e inativos) e a Presidente da SOPEFS informou aos pediatras, via telefone, e-mail, WhatsApp e presencialmente sobre o objetivo da pesquisa. Por fim, ocorreu o envio dos questionários via e-mail e para aqueles que preferiram foram realizadas entrevistas presencialmente. 
Variáveis - $\mathrm{Na}$ atual etapa da pesquisa, foram analisadas as seguintes variáveis: idade, sexo, subespecialidade, especialização residência, título de especialista, registro da especialidade como pediatra, atuação em outros municípios, ano que iniciou as atividades em Feira de Santana.

Análise - Os dados coletados foram digitados em banco de dados e processados no Epi Info 7.0, programa de domínio público (BÓS, 2012). Foi realizada análise descritiva e construção de tabelas e gráficos.

\section{RESULTADOS E DISCUSSÃO}

Identificamos 161 pediatras na busca dos cadastros da SOPEFS e da residência médica de pediatria. Dentre esses dois já faleceram e três mudaram de especialidade. Participaram do atual estudo 61 pediatras.

Desta amostra, as mulheres representam 65,94\%, com inserção crescente no mercado de trabalho ao longo do tempo e maior frequência entre os anos 2010 e 2018 (Gráfico 1). De um modo geral estudos tem relatados maior participação das mulheres na profissão médica no Brasil (CASSENOTE; SCHEFFER, 2013), com especialização principalmente na área de pediatria, ginecologia e obstetrícia. Esse fenômeno em parte é justificado pelo "senso comum" de que algumas áreas têm um estereotipo mais feminino, em detrimento de outras áreas que exigem maior esforço físico (ÁVILA, 2014; CASSENOTE; SCHEFFER, 2013). Do mesmo modo, em outros países, a exemplo do Canadá está ocorrendo entrada crescente de mulheres na pediatria (CMA, 2017).

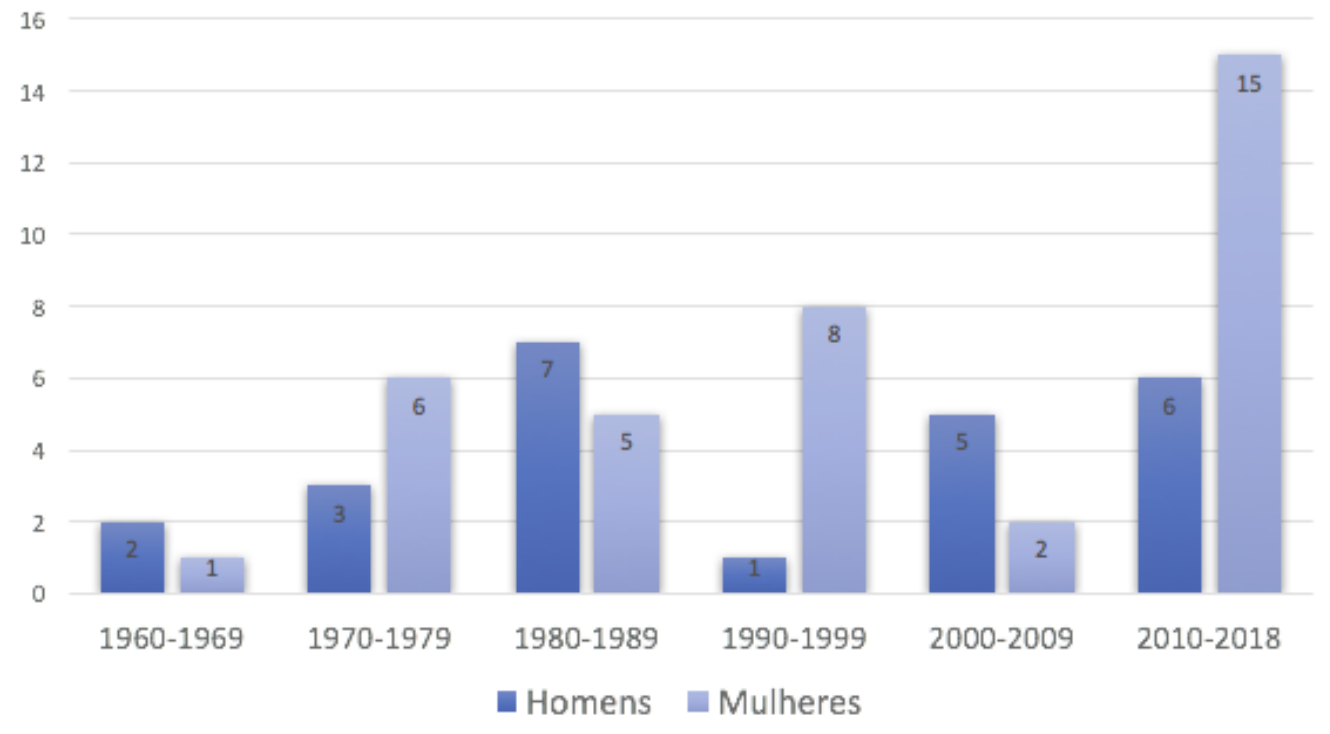

Gráfico 1 - Época de inserção dos pediatras no mercado de trabalho em Feira de Santana, por sexo e ano.

Quanto a faixa etária dos pediatras que atuam no município percebemos que $50,82 \%$, hoje, tem até 48 anos, e a maior concentração desses é na faixa etária de 29-38 anos (Tabela 1). O expressivo incremento na população de pediatras que começaram a atuar na cidade Feira de Santana, ocorreu com a implantação da residência médica no Hospital Estadual da Criança em março de 2012 e expansão do número de vagas (de quatro para doze) em 2015. No período de 2012 a 2018 já foram formados 35 residentes 
e, segundo a coleta de dados realizada em 2018, 25 trabalham em algum serviço de pediatria do município (JORNAL GRANDE BAHIA, 2018)

No que diz respeito a formação profissional dos pediatras feirenses, constatamos que $68,85 \%$ fizeram residência médica, e 52,45\% possuem título de especialista ou registro da especialidade (Tabela 1). Dentre os que fizeram residência médica 52,38\% (22/42) possuem título de especialista. No campo da subespecialidade, 55,73\% se dedicam a alguma subárea da pediatria (Tabela 1).

Tabela 1 - Distribuição dos 61 pediatras por faixa etária, subespecialização, residência médica e título de especialista.

\begin{tabular}{ccccccccccccccc}
\hline $\begin{array}{c}\text { Faixa etária } \\
\text { (anos) }\end{array}$ & \multicolumn{4}{c}{} & \multicolumn{4}{c}{ Subespecialidade } & \multicolumn{3}{c}{ Residência médica } & \multicolumn{3}{c}{$\begin{array}{c}\text { Título de especialista e/ou } \\
\text { Registro da especialidade }\end{array}$} \\
\hline & $\mathrm{N}$ & $\%$ & $\mathrm{Sim}$ & $\%$ & Não & $\%$ & Sim & $\%$ & Não & $\%$ & Sim & $\%$ & Não & $\%$ \\
\hline $19-28$ & 3 & 4,92 & 0 & - & 3 & 4,92 & 3 & 4,92 & 0 & 0 & 0 & - & 3 & 4,92 \\
$29-38$ & 19 & 31,15 & 10 & 16,39 & 9 & 14,75 & 17 & 27,86 & 2 & 3,27 & 7 & 11,47 & 12 & 19,67 \\
$39-48$ & 9 & 14,75 & 7 & 11,47 & 2 & 3,27 & 7 & 11,47 & 2 & 3,27 & 7 & 11,47 & 2 & 3,27 \\
$49-58$ & 10 & 16,39 & 7 & 11,47 & 3 & 4,92 & 9 & 14,75 & 1 & 1,63 & 5 & 8,20 & 5 & 8,20 \\
$59-68$ & 14 & 22,95 & 10 & 16,39 & 4 & 6,55 & 6 & 9,83 & 8 & 13,11 & 9 & 14,75 & 5 & 8,20 \\
$69-78$ & 5 & 8,20 & 0 & - & 5 & 8,20 & 0 & - & 5 & 8,20 & 3 & 4,92 & 2 & 3,27 \\
$\geq 79$ & 1 & 1,64 & 0 & - & 1 & 1,64 & 0 & - & 1 & 1,64 & 1 & 1,64 & 0 & 0 \\
\hline Total & 61 & 100 & 34 & 55,72 & 27 & 44,25 & 42 & 68,83 & 19 & 31,12 & 32 & 52,45 & 29 & 47,53 \\
\hline
\end{tabular}

Constatamos que $57 \%$ dos pediatras trabalham em outro município, além de Feira de Santana, com deslocamento de até $200 \mathrm{~km}$ (Gráfico 2); desses 60\% possuem residência médica em Pediatria. Para melhor compreender este fenômeno é necessário em pesquisas posteriores questionar aos pediatras o motivo que os levam a buscar outras cidades para o exercício da Pediatria. Vale ressaltar que a interiorização da medicina, sobretudo quando ocorre por profissionais qualificados, traz grandes benefícios aos serviços de saúde e a população por eles assistida.

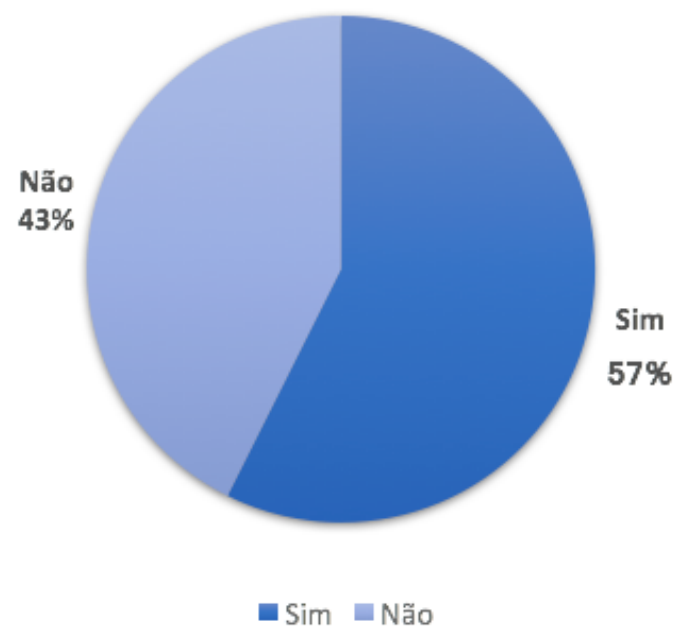

Gráfico 2 - Pediatras que trabalham em outra cidade além de Feira de Santana 


\section{CONCLUSÕES}

$\mathrm{Na}$ avaliação do perfil dos pediatras que atendem em Feira de Santana, notamos que a metade deles tem idade menor que 48 anos. Mais da metade possui residência médica, título de especialista ou registro da especialidade, bem como atuam em uma subespecialidade da Pediatria. Chamou a nossa atenção o predomínio de mulheres na amostra estudada e o exercício da Pediatria em outras cidades circunvizinhas.

\section{REFERÊNCIAS}

ÁVILA, R. C. Formação das mulheres nas escolas de medicina. Rev. bras. educ. méd, v. 38, n. 1, p. 142-149, 2014.

BÓS, A. J. G. Epi Info sem mistérios: um manual prático [recurso eletrônico]. Porto Alegre: EDIPUCRS, 2012. Acesso em: 01 ago. 2018.

CANADIAN MEDICAL ASSOCIATION (CMA). Workforce Survey, 2017. Disponível em: $\quad<$ https://www.cma.ca/Assets/assetslibrary/document/en/advocacy/profiles/pediatrics-e.pdf>. Acesso em: 02 ago. 2018.

JORNAL GRANDE BAHIA. Feira de Santana: Hospital Estadual da Criança forma a $\mathbf{5}^{\text {a }}$ turma de residentes médicos. 24 fev. 2018. Disponível em $<$ http://www.jornalgrandebahia.com.br/2018/02/feira-de-santana-hospital-estadual-dacrianca-forma-5o-turma-de-residentes-medicos/>. Acesso em: 03 de ago. 2018.

SANTIAGO, L.B.; et al. Incentivo ao aleitamento materno: a importância do pediatra com treinamento específico. Jornal de Pediatria, [S.I], v. 79, n. 6, 2003.

SCHEFFER, M. C.; CASSENOTE, A. J. F. The feminization of medicine in Brazil. Revista Bioética, v. 21, n. 2, p. 268-277, 2013. 